\title{
Single nucleotide polymorphisms (SNPs) at CDH1 promoter region in familial gastric cancer
}

\author{
A. Ramos-de la Medina, H. More ${ }^{1}$, H. Medina-Franco², B. Humar' ${ }^{1}$, A. Gamboa ${ }^{2}$, L. J. Ortiz ${ }^{2}$, \\ J. H. Donohue and P. Guilford ${ }^{1}$
}

Department of Surgery. Mayo Clinic. Rochester. Minnesota. EE.UU. ' Department of Biochemistry. Cancer Genetics Laboratory. University of Otago. Dunedin, New Zealand. ${ }^{2}$ Departments of Surgery and Pathology. Instituto Nacional de Ciencias Médicas y Nutrición "Salvador Zubirán”. México. D.F. México

\begin{abstract}
Introduction: gastric cancer is the most frequent gastrointestinal malignancy in Mexico and the proportion of patients younger than 40 years is one of the highest reported in the world literature. Recently several families with familial diffuse gastric cancer have been identified at the National Institute of Medical Sciences and Nutrition. Germline mutations in the $\mathrm{E}$-cadherin gene (CHD1) have been described that result in the development of diffuse hereditary gastric cancer in young patients.

Methods: the complete coding sequence at exons 1 to 16 and the promoter region of $\mathrm{CDH} 1$ was amplified by polymerase chain reaction in peripheral blood samples of two patients with early onset familial diffuse gastric cancer.

Results: no germline inactivating mutations of CHD1 were found on either patient. Single nucleotide polymorphisms $-160 \mathrm{C} \rightarrow \mathrm{A}$ were detected in the promoter region of $\mathrm{CDH} 1$ in both patients.

Conclusions: the polymorphism $-160 \mathrm{C} \rightarrow \mathrm{A}$ theoretically confers an increased risk of developing diffuse gastric cancer. The relatives of these patients may an increased risk of gastric cancer among other tumors. There is presently not enough evidence to consider the $-160 \mathrm{C} \rightarrow \mathrm{A}$ polymorphism an etiologic factor of diffuse gastric cancer in these patients since the frequency and type of genetic alterations of $\mathrm{CDH} 1$ are largely unknown in the Mexican population. It will be necessary to conduct epidemiologic studies in the Mexican population to determine the influence that genetic alterations have on the genesis of diffuse gastric carcinoma.
\end{abstract}

Key words: Hereditary diffuse gastric cancer. E-cadherin. SNP. Genetics. Young patients.

Recibido: 06-04-05.

Aceptado: 28-04-05.

Correspondencia: Antonio Ramos-de la Medina. Advanced GI Surgical Fellow. Department of Surgery. Mayo Clinic College of Medicine. 200 First Street SW. Rochester, MN 55905. USA. Fax: 507-284-5196. e-mail: ramos.antonio@mayo.edu
Ramos-de la Medina A, More H, Medina-Franco H, Humar B, GamboaA, Ortiz LJ, Donohue JH, Guilford P. Polimorfismos de nucleótido único (SNPS) en la región promotora $C D H 1$ en cáncer gástrico familiar. Rev Esp Enferm Dig 2006; 98: 36-41.

\section{INTRODUCTION}

Gastric cancer (GC) represents the second most frequent neoplasm worldwide (1). The vast majority of cases of GC occur between the ages of 50 and 70 years. In Mexico, GC is the most frequent neoplasm of the gastrointestinal tract (2) and the proportion of patients younger than 40 years of age is one of the highest reported (3). The causes behind this high proportion of young patients have not been explained. In general, the development of GC is considered to be the consequence of a complex interaction between genetic, infectious and dietary factors. With increasing frequency there are reports about the influence of heredity in GC. Epidemiologic studies have shown that first degree relatives of GC patients have a risk 2 to 3 times higher of developing GC that the general population $(4,5)$. In addition, the Scandinavian Twins Study found an increased risk for GC in the twin sibling of an affected person (6). Germline mutations of the E-cadherin gene (CDH1) associated with the development of diffuse GC were first described in 1998 (7). E-cadherin has a fundamental role in establishing and maintaining in intercellular adhesion and epithelial architecture (8). Inactivating mutations in this gene are the most frequent genetic alterations found in hereditary diffuse and sporadic GC. E-cadherin is currently considered a tumor suppressor gene and its alterations are associated with increased susceptibility to several types of cancer (9). In spite of the advances in the knowledge of pathogenesis, little is know about the effect that genetic sus- 
ceptibility has on the occurrence of gastric neoplasms. A recently published study on GC in patients younger than 40 years old at the National Institute of Medical Sciences and Nutrition "Salvador Zubirán" (NIMSNSZ) found that $17 \%$ of the cases had a history of GC in first degree relatives and identified 5 families with diagnostic criteria for hereditary gastric cancer (HGC) (3). The objective of this study is to report the absence of inactivating mutations of $\mathrm{CDH} 1$ and the presence of single nucleotide polymorphisms (SNP) in CDH1 in 2 members of these families and to discuss the implications that these findings have in the diagnosis and treatment of the patients.

\section{MATERIAL AND METHODS}

The complete coding sequence of CDH1 (exons 1 to 16) was amplified by polymerase chain reaction (PCR) with the technique described previously by one of the authors (PG) (7) in peripheral blood samples of two patients of 25 (patient 1) and 34 (patients 2) years old respectively with histopathological diagnosis of early onset diffuse GC identified at the NIMSNSZ. Both cases were of Mexican ancestry, mestizo origin, lived in different areas of the country, were not related and had a family history of diffuse GC in at least one first degree relative diagnosed before de age of 40 years. Patient 1 came from a family with all the diagnostic criteria for HGC (Fig. 1). Patient 2 had a positive family history of diffuse GC diagnosed in his father at 38 years old.

The promoter region of CDH1 was amplified by PCR using the forward primer 5'-AATTAACCCTCACTAAAGAGTGAGCCCCATCTCCAAAA-3' and the reverse

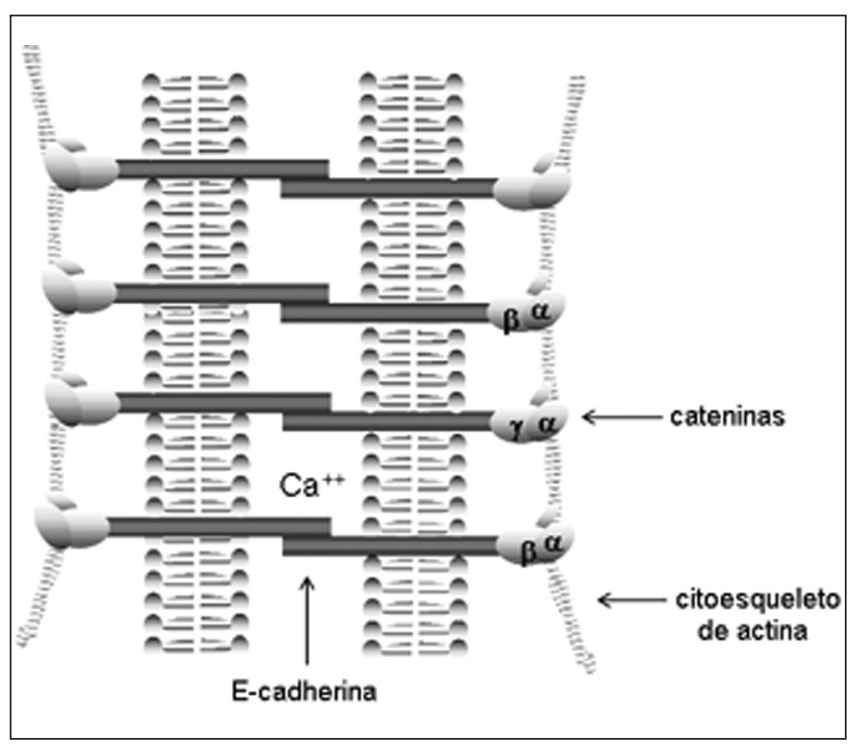

Fig. 1.- Interacción entre las moléculas de E-cadherina, las cateninas $\beta / \gamma$ $y$ las cateninas $\alpha$ con el citoesqueleto de actina. primer 5'-TGACTTCCGCAAGCTCACA-3' at an annealing temperature of $65^{\circ} \mathrm{C}$ with $2 \mathrm{mM}$ of $\mathrm{MgCl} 2$ and $5 \%$ DMSO. A T3 tale adhered to the forward primers allowed the sequencing of the PCR products using a T3 primer labeled with IR800 (MWG-Biotech). The sequenced products were analyzed in a LI-COR 4000L DNA sequencer (LI-COR Nebraska) according to the protocol provided by the manufacturer. $\mathrm{CDH} 1$ variants were confirmed by independent PCR and reverse sequencing.

\section{RESULTS}

No germline inactivating mutations of CHD1 were found on either patient. A single nucleotide polymorphism (SNP) -160 C $\rightarrow$ A was detected in the promoter region of CDH1 in both patients (Fig. 2). A sequence alteration in intron 1 , nucleotide position $48+6 \mathrm{~T} \rightarrow \mathrm{C}$ was detected in patient 2 .

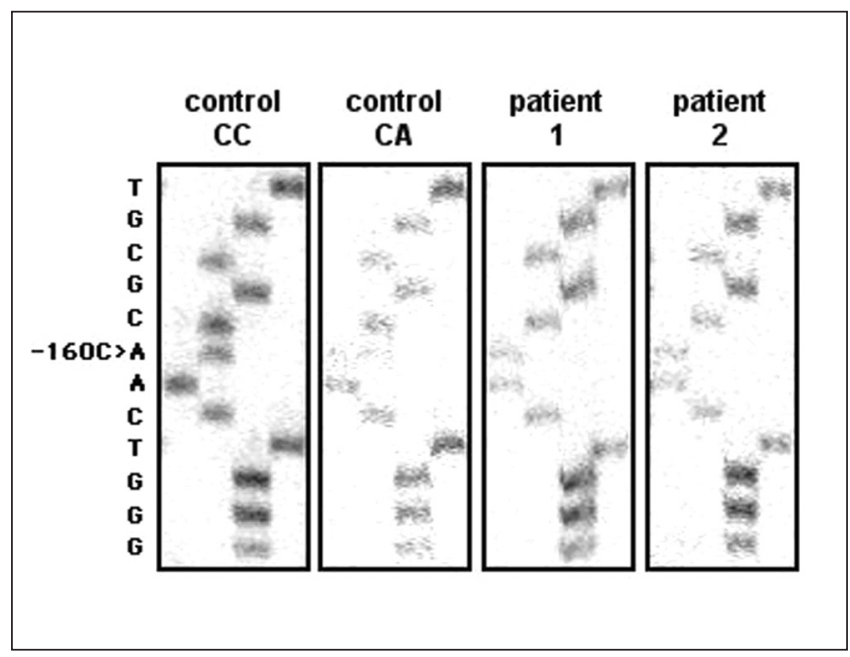

Fig. 2. - Detección del polimorfismo-160 C $\rightarrow$ A del gen CDH1 mediante análisis de $P C R$.

\section{DISCUSSION}

The identification of genes that predispose to familial cancer syndromes constitutes a fundamental advancement in the understanding of the genesis of neoplasms. In Mexico, the ratio of patients with GC younger than 40 years of age is high and a significant proportion of this population has familial aggregation (3). There are few studies that explore the influence that genetic factors have on the high frequency of GC in the Mexican population $(10,11)$.

E-cadherin is a membrane protein whose main function is the preservation of epithelial integrity by main- 
taining intercellular adhesion and cell polarity (Fig. 3) $\mathrm{CDH} 1$ the coding gene for E-cadherin is located in chromosome 16q22.1. E-cadherin dysfunction is associated with the development of high grade cancers, invasion and metastasis of several neoplasms (10-15).

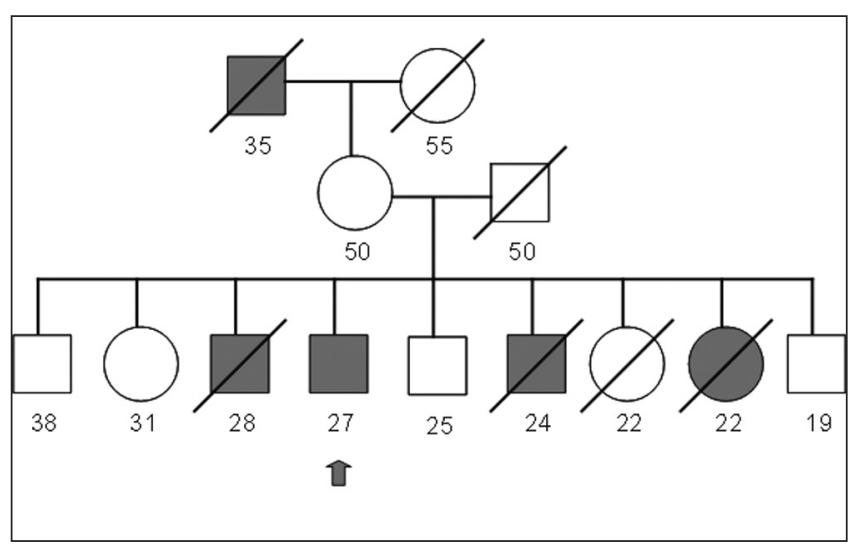

Fig. 3. - Pedigrí del paciente 1. Cuadros, hombres, círculos, mujeres, diagonales, muertos. Todos lo pacientes en sólido han tenido diagnóstico de cáncer gástrico difuso.

Germline mutations of CDH1 responsible for the development of high grade diffuse GC in young patients were described for the first time in 1998 (7). These mutations have an autosomal dominant pattern of inheritance with incomplete penetrance. The efficacy of endoscopic screening for this form of diffuse GC is poor because it tends to present as submucosal infiltration instead of as an exophytic mass. To date there are only 3 reports on the use of prophylactic gastrectomies in 11 patients with inactivating germline mutations of $\mathrm{CDH} 1$ (16-18). CDH1 mutations are considered the most frequent somatic alteration found in diffuse GC since they are present in more than $50 \%$ of the cases (19). In the present study no germline inactivating mutations of CDH1 were identified, hence the difficulty of giving recommendations regarding followup and management for these patients and their families based on this.

Recently, Li et al. described a SNP C $\rightarrow$ A at position -160 in the promoter region of $\mathrm{CDH} 1$ with a direct effect in the transcriptional regulation of $\mathrm{CDH} 1$ in a prostate cancer cell line. This polymorphism is associated with a $68 \%$ reduction of the $\mathrm{CDH} 1$ transcriptional activity in vitro (20). A recent study on Italian patients showed that the $-160 \mathrm{C} \rightarrow \mathrm{A}$ polymorphism at the $\mathrm{CDH} 1$ promoter region confers and increased risk of developing sporadic diffuse GC (21). This study performed polymorphism genotyping at positions $-160 \mathrm{C} \rightarrow \mathrm{A}, \quad 48+6 \mathrm{~T} \rightarrow \mathrm{C} \quad \mathrm{y}$ $2076 \mathrm{X} \rightarrow \mathrm{T}$, finding that haplotype A-T-C is associated with an increased risk. Two other studies, one in Korean patients and other in Taiwanese patients did not find any association between the $-160 \mathrm{C} \rightarrow \mathrm{A}$ polymorphism and GC $(22,23)$. The disagreement between these studies could be secondary to differences in genetic backgrounds and environmental factors among ethnic groups.

The most common genetic variation is the SNP which occurs with a frequency of at least 1 for every 1.000 base pairs of the approximately 3.2 billion than form the human genome. For a variation to be considered a SNP it needs to occur in at least $1 \%$ of the population. Most SNPs occur at non-coding regions of the genome and hence do not manifest phenotypically (24), nevertheless, it has been shown that when SNPs occur at the promoter region of a gene, they can have an important effect on transcription (25). The identification of the $-160 \mathrm{C} \rightarrow \mathrm{A}$ polymorphism in these 2 patients theoretically confers them an increased risk of GC. The family members of these patients have an increased risk of diffuse GC and other neoplasms. Although there is not enough evidence to consider the $-160 \mathrm{C} \rightarrow \mathrm{A}$ polymorphism as an etiologic factor of diffuse $\mathrm{GC}$, its relationship to an increased risk in the carriers may be secondary to association with one or more additional polymorphisms within or near the CDH1 gene. Since the frequency and type of mutations in $\mathrm{CDH} 1$ in the Mexican population is unknown, it is difficult to estimate the risk that this polymorphism confers. Careful screening in the family members of these patients is of utmost importance. Nevertheless, despite frequent endoscopic evaluation with multiple biopsies, one family member of patient 1 was recently diagnosed with diffuse GC with submucosal extension and peritoneal metastasis. The use of prophylactic gastrectomy in the patients at risk is not recommended in the absence of inactivating mutations of CHD1. One option that has been explored by some groups is the use of chromo-endoscopy and biopsy of suspicious areas. It will be necessary to conduct epidemiologic studies in the Mexican population to determine the influence that genetic alterations have on the genesis of diffuse gastric carcinoma.

\section{REFERENCES}

1. Parkin DM, Pisani P, Ferlay J. Estimates of the worldwide incidence of eighteen major cancers in 1985. Int J Cancer 1993; 54: 594-606.

2. Villalobos JJ, Vargas F, Villarreal HA, et al. Estudio prolectivo de 10 años de cáncer del aparato digestivo. Rev Gastroenterol Mex 1990; 55: 17-24.

3. Ramos-De la Medina A, Salgado-Nesme N, Torres-Villalobos G, Medina-Franco H. Clinicopathologic characteristics of gastric cancer in a young patient population. J Gastrointest Surg 2004; 8: 240-4.

4. Palli D, Galli M, Caporaso NE, et al. Family history and risk of stomach cancer in Italy. Cancer Epidemiol Biomarkers Prev 1994; 3: 15-8.

5. Lissowska J, Groves FD, Sobin LH, et al. Family history and risk of stomach cancer in Warsaw, Poland. Eur J Cancer Prev 1999; 8: 223-7.

6. Lichtenstein P, Holm NV, Verkasald PK, et al. Environmental and heritable factors in the causation of cancer. Analysis of cohorts of twins from Sweden, Denmark and Finland. N Engl J Med 2000; 343: 78-85.

7. Guilford P, Hopkins J, Harraway J, McLeod M, McLeod N, Harawira $\mathrm{P}$, et al. E-cadherin germline mutations in familial gastric cancer. $\mathrm{Na}-$ ture $1998 ; 392:$ 402-5. 
8. Takeichi, M. Cadherin cell adhesion receptors as a morphogenetic regulator. Science 1991; 251: 1451-5.

9. Christofori G, Semb H. The role of the cell-adhesion molecule E-cadherin as a tumour-suppressor gene. Trends Biochem Sci 1999; 24: 73-6.

10. Herrera-Goepfert R, Zúñiga J, Hernández-Guerrero A, RodríguezReyna T, Osnalla N, Ruiz-Morales J, et al. Association of the HLADQB*0501, allele of the major histocompatibility complex with gastric cancer in Mexico. Gac Med Mex 2004; 140: 299-303.

11. Garza-González E, Hold G, Pérez-Pérez GI, Bosques-Padilla FJ, Tijerina-Menchaca R, Maldonado-Garza HJ, et al. Role of polymorphism of certain cytokines in gastric cancer in Mexico. Preliminary results Rev Gastroenterol Mex 2003; 68: 107-12.

12. Umbas JA. Schalken TW, Aalders, et al. Expression of the cellular adhesion molecule e-cadherin is reduced or absent in high-grade prostate cancer. Cancer Res 1992; 52: 5104-9.

13. Li YJ, Meng YX, Ji XR. Relationship between expressions of E-cadherin and alpha-catenin and biological behaviors of human pancreatic cancer. Hepatobiliary Pancreat Dis Int 2003; 2: 471-7.

14. Yoshida R, Kimura N, Harada Y, Ohuchi N. The loss of E-cadherin, alpha- and beta-catenin expression is associated with metastasis and poor prognosis in invasive breast cancer. Int $\mathrm{J}$ Oncol 2000; 18: 51320.

15. Graziano F, Arduini F, Ruzzo A, Bearzi I, Humar B, More H, et al. Prognostic analysis of E-cadherin gene promoter hypermethylation in patients with surgically resected, node-positive, diffuse gastric cancer. Clin Cancer Res 2004; 10: 2784-9.

16. Huntsman DG, Carneiro F, Lewis FR, MacLeod PM, Hayashi A, Monaghan $\mathrm{KG}$, et al. Early gastric cancer in young, asymptomatic carriers of germ-line E-cadherin mutations. N Engl J Med 2001; 344 : 1904-9.

17. Chun YS, Lindor NM, Smyrk TC, Petersen BT, Burgart LJ, Guilford PJ, et al. Germline E-cadherin gene mutations: is prophylactic total gastrectomy indicated? Cancer 2001; 92: 181-7.

18. Lewis FR, Mellinger JD, Hayashi A, Lorelli D, Monaghan KG, Carneiro F, et al. Prophylactic total gastrectomy for familial gastric cancer. Surgery 2001; 130: 612-7.

19. Graziano F, Humar B, Guilford P. The role of the E-cadherin gene $(\mathrm{CDH} 1)$ in diffuse gastric cancer susceptibility: from the laboratory to clinical practice. Ann Oncol 2003; 14: 1705-13.

20. Li LC, Chui RM, Sasaki M, Nakajima K, Perinchery G, Au HC, et al. A single nucleotide polymorphism in the E-cadherin gene promoter alters transcriptional activities. Cancer Res 2000; 60: 873-6.

21. Humar B, Graziano F, Cascinu S, Catalano V, Ruzzo AM, Magnani $\mathrm{M}$, et al. Association of CDH1 haplotypes with susceptibility to sporadic diffuse gastric cancer. Oncogene 2002; 21: 8192-5.

22. Park WS, Cho YG, Park JY, Kim CJ, Lee JH, Kim HS, et al. A single nucleotide polymorphism in the E-cadherin gene promoter-160 is not associated with risk of Korean gastric cancer. J Korean Med Sci 2003; 18: 501-4.

23. Wu MS, Huang SP, Chang YT, Lin MT, Shun CT, Chang MC, et al Association of the $-160 \mathrm{C} \rightarrow \mathrm{A}$ promoter polymorphism of E-cadherin gene with gastric carcinoma risk. Cancer 2002; 94: 1443-8.

24. Erichsen HC, Chanock SJ. SNPs in cancer research and treatment. Br J Cancer 2004; 90: 747-51.

25. Hagmann M. Human genome. A good SNP may be hard to find. Science $1999 ; 285: 21-2$. 